\title{
Perception and Satisfaction with Received Information Regarding Treatment for Intestinal Parasitic Infections in Cuban Patients
}

\author{
R Cañete $^{1}$, K Brito ${ }^{2}$, D Guilhem ${ }^{3}$, KW Goodman ${ }^{4}$
}

\begin{abstract}
Objective: To determine patients'perceptions and satisfaction with received information regarding treatment for intestinal parasitic infection in a public health institution.

Methods: Data from this descriptive, cross-sectional study were collected through an open questionnaire administered to patients who sought treatment for intestinal parasite infection during December 2013 at the provincial Centre of Hygiene, Epidemiology and Microbiology, in Matanzas, Cuba. Seventy-eight out of 152 patients agreed to participate in the study, signed the informed consent form and were included in the final analysis.

Results: Seventy-eight patients (51.32\%) completed the questionnaire with a balanced proportion by gender. The majority of respondents (87.18\%) was aware of intestinal parasites and their impact on human health but did not recognize that clinical parasitologist were the most appropriate professionals to treat parasites. The majority (89.74\%) agreed that it was ethically correct to receive full information about the parasite's characteristics, the available drugs or alternatives to treatment and the adverse events associated with medication. Most of the respondents were willing to return in case of need declaring their satisfaction with the care they received.

Conclusion: Our findings suggest that more inclusion of patients in the treatment process will increase their positive perceptions and satisfaction with health providers.
\end{abstract}

Keywords: Health communication, intestinal parasites, patient satisfaction, public health, therapeutics

\section{Percepción y Satisfacción con la Información Recibida sobre el Tratamiento para la Infeccións Parasitaria Intestinal en Pacientes Cubanos}

\author{
R Cañete ${ }^{1}$, K Brito ${ }^{2}$, D Guilhem ${ }^{3}$, KW Goodman ${ }^{4}$
}

\begin{abstract}
RESUMEN
Objetivo: Determinar la percepción y satisfacción sobre la información recibida en relación con el tratamiento de infecciones por parásitos intestinales.

Material y métodos: Se realizó un estudio descriptivo en el que se colectó información a través de la aplicación de un cuestionario abierto a pacientes que solicitaron tratamiento por infecciones parasitarias intestinales en el Centro Provincial de Higiene, Epidemiologia y Microbiología de Matanzas, Cuba durante el mes de diciembre de 2013.

Resultados: Setenta y ocho pacientes de 152 aceptaron participar en el estudio. La mayoría de los participantes tenían información sobre parásitos intestinales y su impacto negativo en la salud pública, sin embargo, no reconocían al parasitólogo clínico como el profesional más capacitado para su tratamiento. El 89,74\% consideró éticamente correcto recibir información detallada sobre las parasitosis, las alternativas de tratamiento y los eventos adversos que podrían aparecer como consecuencia de la utilización de esos medicamentos. Casi la totalidad mostró satisfacción con la información y el tratamiento recibido y expresaron su deseo de regresar en caso de necesidad.
\end{abstract}

From: ${ }^{1}$ University of Medical Sciences and Center of Hygiene, Epidemiology and Microbiology, Matanzas City, Cuba, ${ }^{2}$ University of Medical Sciences and Provincial Odontology Clinics, Matanzas City, Cuba, ${ }^{3}$ Faculty of Medical Sciences, University of Brasilia, Brazil and ${ }^{4}$ University of Miami Bioethics Program, Florida, United States of America.
Correspondence: Professor R Cañete, Research Ethics Committee of the Provincial Centre of Hygiene, Epidemiology and Microbiology, Matanzas City, Cuba. Email: roberto.villafranca@infomed.sld.cu 
Conclusión: Los resultados de este estudio sugieren que una mayor inclusión de los pacientes en la solución de sus problemas de salud podría incrementar su satisfacción con los servicios que reciben en las instituciones públicas.

Palabras clave: Salud pública; comunicación en salud; tratamiento; satisfacción; parásitos intestinales.

West Indian Med J 2016; 65 (3): 520

\section{BACKGROUND}

Intestinal protozoa and soil-transmitted helminths still continue to cause significant health problems worldwide, especially in the tropical and sub-tropical regions (1). Most of those parasites exist and persist for social and economic reasons that enable pathogens to take advantage of changes in the behavioural and physical environment (2).

It is known that the transmission of enteroparasites depends on the presence of infected individuals, sanitation deficiencies and, principally, the socio-economic and cultural conditions of the population (3) so the frequency of those infections are common in resource limited settings. Therefore, the adequate diagnosis, treatment and follow-up of the infected population could play a pivotal role in the control of parasitic infections.

Once diagnosed, the intestinal parasitic infection (IPI) needs to be treated. Patient's thoughts and cultural behaviours influence the process, causing at times, difficulties with clinicians and their institutions. This is particularly important in resource limited settings, where traditional therapies and religious beliefs are preferred by some rather than using western medicine.

It is universally recognized that clinicians have a unique understanding of diseases, therapies, and the expected outcomes of treatment, all of which are essential to sound medical decision-making. Even with the clinician's relative advantage in knowledge and training, patients' thoughts and cultural beliefs must be respected and considered (4). Clinicians are generally held in high-esteem by society and have strong professional obligations to act for the benefits and protection of patients.

There is an important conceptual distinction between clinicians' involvement in a decision-making process and having sole authority over the final decision. Clinicians can play a strong advisory role and thereby contribute importantly to the decisions without having sole decisional authority. Clinicians should play the role of "adviser" rather than "decider" (4).

Cuba is a low-income country suffering resource limitation. The public health system, however, is strong, fully structured, prevention-oriented and gives special attention to continuing medical education and patient satisfaction $(5,6)$.

Although patient autonomy and understanding is increasingly recognized as critically important, paternalism by physicians is prevalent in Cuba and is reinforced by the fact that patients also have a great deal of trust in their doctors. Moreover, patients could prevent the recurrence of intestinal parasitic infections if they knew how to do so, but may not have the information they need. For these reasons, we asked patients what they understood regarding treatment for intestinal parasitic infection and what information they would have wanted to receive.

The aim of this study was to determine the patients' perceptions and satisfaction with received information regarding treatment for IPI at the provincial Centre of Hygiene, Epidemiology and Microbiology in Matanzas, Cuba.

\section{SUBJECTS AND METHODS \\ Design and study site}

This descriptive, cross-sectional study was carried out in December 2013 at the Department of Parasitology of the provincial Centre of Hygiene, Epidemiology and Microbiology (CHEM) in Matanzas, Cuba.

The CHEM, located in the city of Matanzas, is an institution associated with the provincial representation of the Cuban Ministry of Public Health. This government-funded and public facility is responsible for monitoring all health conditions and for keeping the population safe from epidemics or outbreaks.

As a provincial representative and administrative department, the centre has the mission to supervise medical activities and environmental safety. It advises the local authorities on health issues and has responsibility to conduct educational programmes of residents on different medical specialties (Microbiology-Hygiene and Epidemiology) and technicians from Clinical and Microbiology Laboratories.

\section{Participant selection}

Individuals from 20 to 70 years of age who sought treatment for IPI and who agreed to participate and signed the informed consent form were accepted into the study. Potential participants were excluded if any of the following conditions were present: (a) they had a psychological disorder, (b) were participating in other study or (c) were professionals or students of medical sciences. Additionally, volunteers who failed to complete the questionnaire were also excluded. Seventy-eight potential participants out of 152 persons eligible met the inclusion criteria, filled out the questionnaire and were included in the final analysis.

\section{Data collection \\ Questionnaire}

An open questionnaire was designed by the authors, peer-reviewed and discussed with all members of the Scientific Council of the CHEM prior the beginning of study. The 
questionnaire (Appendix 1) was focussed in the following study objectives: (a) general knowledge about intestinal parasites and its negative implications for human health; (b) opinions about what professional, ideally, should treat intestinal parasites; (c) the importance of communication with clinicians; (d) opinions about the therapeutic alternatives and the role of patients' believes and (e) barriers to receiving or sharing information about the parasites characteristics, available drugs or alternatives for treating them and the adverse events associated with medication. Demographic information such as age and gender were also recorded. Finally, we asked patients whether they would be able to return to the institution if needed and about their satisfaction with the care they received.

\section{Procedure}

Open questionnaires were administered in the conference room (a neutral, quiet and familiar place) of the centre. A technician, who works at the Parasitology Department contacted potential participants, explained the study, answered questions and invited them to participate. When participants filled out the questionnaire, only a technician from another department was present. Neither phones nor other mobile devices were allowed in the conference room during the process.

Ethical clearance was granted by our Institutional Review Board as well as an independent group of advisors selected by the director of the CHEM from different departments. Volunteers were fully informed about the aim of the study and the possible implications of the results. They were told that their participation was optional. The enrollment also required the informed consent form signed by all participants.

Data were entered and analysed using EpiInfo 6.04 software (Public Health Domain Software, CDC, Atlanta, GA, USA). Initial data entry was cross-checked by two independent individuals in order to be sure that information was correctly added.

\section{RESULTS}

The mean age of the participants was $42 \pm 11.7$, with a balanced proportion of women 40/78 (51.28\%) and men 38/78 $(48.72 \%)$. Nine participants were studying from different Cuban Universities, sixty-nine were already graduated. Sixty (76.92\%) out of 78 participants were living in urban areas.

The majority of respondents $(87.18 \%)$ had general information about IPI and its negative implication on human health and recognized clinical parasitologists as the appropriate professionals to treat intestinal parasites in an infected population.

On the contrary, $12.82 \%$ respondents did not demonstrated general knowledge about IPI. For them, IPI was only restricted to "Giardia", "Amoebas", pinworms or some roundworms. No information was demonstrated by respondents about how to avoid the infections or what medication could be used for the treatment of IPI. For this group, intestinal parasites only produce light abdominal pain or occasionally a diarrhoeal episode easily eliminated with traditional home therapies. This group also considered any clinician as adequate for treating IPI because, in their opinion, all doctors received the same programme in their training. They did not know anything about the existence of clinical parasitologists, their functions in the healthcare system, or where to find those professionals in case of need.

All participants recognized the importance of good communication with the clinician and the need of evaluation in common the therapeutic alternatives. The majority (89.74\%) agreed that it was ethically correct to receive full information about the parasite's characteristics, the available drugs, the treatment alternatives and the adverse events associated with medication.

A scant $10.26 \%$ of respondents were not interested in any information and were only interested in receiving the treatment for their infection. The place of living was associated significantly with participants' interest on information (RR 1.45 ; 95\% CI 1.04-2.01). Participants form urban areas were more interested than those from rural communities $(p<0.01)$. Most respondents (70 out of 78) were willing to return if needed and indicated their satisfaction with the attention received from the health personnel of the centre. It is important to remark on some important comments received from $70 \%$ responders about satisfaction when they visited other professionals and institutions on the province. In our opinion those comments must be taken into consideration to improve health attention around the province.

For those respondents, there were at least four reasons that could be addressed by authorities to reach excellence in healthcare: (a) health professionals need to reorganize their schedule and provide more time for each patient, (b) public health leaders need to implement an updated training programme about IPI, bioethics and communicational skills for health professionals, (c) patients need to take a more active role in the treatment decision-making process and (d) informed consent processes should accompany all public health interventions.

\section{DISCUSSION}

In the last few decades, patient satisfaction has become an important endpoint in the assessment of the quality of care, which is increasingly required by accreditation agencies in monitoring of the quality of hospital or ambulatory care. Moreover, satisfaction with care may influence patient compliance to treatment and consequently, impact on disease outcome $(4,7)$. In this study, the majority of respondents were aware of IPI and its negative impact on human health. This positive result is consistent with the Cuban national effort to provide high quality care based on health prevention (6-9).

The importance of patient's perceptions about the causes of their diseases has been emphasized (10). Even when people live in countries with accessible health and educational systems, like Cuba, providers need to ask about individual general knowledge about infectious diseases and IPI, in particular. Our findings showed that around $13 \%$ of respondents do not 
have a clear knowledge about that topic and underestimate the effect of IPI on human health. This could have a significant negative influence at the community level. Without knowing how to avoid IPI, individuals do not know how to prevent new infections, and subsequently, because most of them are asymptomatic, they could be responsible for community dissemination of the IPI.

These data suggest that an important element of the physician-patient interaction is individual responsibility for citizens to be empowered by their physicians to help prevent the spread of disease.

The principle of responsibility is not only a principle for physicians but also a principle for patients. To achieve this goal, the physician-patient relationship need should not be paternalistic, and should recognize that both parties have important responsibilities related to health.

Disadvantaged populations tend to have worse health and higher morbidity and mortality $(11,12)$. In agreement with this statement, the final report of the World Health Organization Commission on the Social Determinants of Health (CSDH), published in 2008, affirmed that social injustice was killing on a grand scale, with a toxic combination of "poor social policies and programmes, unfair economic arrangements, and bad politics' being responsible for producing and reinforcing health inequalities (13).

Common agendas integrating research, practice, and policy-making may highlight the importance of community participation to assure inclusion of all populations in the activities that finally improve the quality of life of all sectors of society. The policymakers' commitment is a key part of this effort; they are responsible for the local, national or regional implementation of programmes that are fully accessible to the public.

In Cuba, there are no reports of some of the most devastating neglected tropical diseases but, as a low-income country, there are still socio-economic limitations that facilitate the spread of IPI, mainly in populations living in rural and mountain communities $(14,15)$. Considering this, professionals, patients, and institutions must create communication strategies to support informed decisions and practice-based on evidence (16).

Another point of discussion is why some patients reject or at least were not interested in receiving information about IPI or the existence of alternatives for treatment if actually they were infected and requested to have treatment.

To understand this, we must analyse Cuban's healthcare system. Health in Cuba is governed by the fundamental basic principles such as the state and social character of medicine, access and universality as well as the implementation of the latest scientific and technology advances that have played an important role in the achievement of the result attained. The Cuban model of primary healthcare has the National Health System as its platform and axis. The health system is tightly organized, and the first priority is prevention. Although Cuba has limited economic resources, the healthcare system has solved some problems that many countries have not yet been able to do $(6,17)$. Vaccination coverage, the existence of programmes for a large number of health disturbances and freeaccessibility services as well as the existence of a basic healthworking group (doctor, nurse, social worker) in each neighborhood.

All previous conditions create in Cubans a deep sensation of safety that induce a thought that their health problems are responsibly exclusively of health professionals. This is our problem now, Cubans need to understand that even with our strong health system they are primarily responsible for their health. In this respect, Cuba is very different from almost all developing countries.

Another important issue is the high-level of our health professionals and the wide range of medical specialties covered. The Tropical Medicine Institute "Pedro Kouri", for example, is the referral institution to diagnose and treat infectious diseases and has several programmes: residencies, masters and doctorates as well as short training periods that increase the competencies in areas related to neglected tropical diseases.

Parasitologists, all trained in that institution, are distributed throughout the country and support, with their research, most of the response to infectious diseases produced by parasites. As part of the hygiene, epidemiology and microbiology system, and leading clinical and laboratory active surveillance, parasitologists keep people free of most of the severe infectious diseases like, malaria, sleeping sickness and filariasis potentially introduced to the country by foreign visitors, or by nationals travelling to endemic areas.

Even when some of the respondents, mainly in rural areas, were not interested to know about IPI, the entire group, those respondents included, recognized the importance of good communication with the clinicians and the evaluation of the therapeutic alternatives. This is a result of the changing paradigm of healthcare in the country that differs from the widespread paternalism of the past (7).

Most respondents were willing to return in case of need and declared their satisfaction with the attention received by health personnel of the centre.

It is important, in our opinion, to refer to our continuing educational programmes and in particular the programmes related to ethics and public health carried out at the Centre for Hygiene, Epidemiology and Microbiology in Matanzas City (18). This programme, which is still running, has been reinforcing the training of health-workers, students and selected community leaders in communication skills, respect for patient autonomy and negotiation.

From patients' point of view, there are some issues that authorities need to consider to improve healthcare in the province. A brief analysis of the patients' referred opinion is reflected here.

Cuban's health professionals have a lot of work. It is common to find a health-worker involved not only in clinical actions but also in research and teaching. These activities de- 
mand a lot of study and training, and health professionals spent great part of their free time studying and doing active search for information about their work. Typical patient meetings with health professionals last no more than 20 minutes. One recognized "problem" here is the patients' needs to talk. As healthcare is totally free, patients ask about each detail or possible details of any health disturbance and the complementary tests available to diagnose any diseases and visit clinical offices for everything they felt could be a disease. The commitment of professionals and patient, are well-designed weapon against diseases.

Other evidence for our context found in this study is the desire of mediation by informed consent process. In Cuba, health professionals always explain about alternative for the treatments and give information for each alternative but it is completely true that doctors felt patients as part of their family and were a bit paternalistic in their decisions. A more negotiated decision and a more active participation of patients in the resolution of health problems is a reality we are now pursuing.

\section{Limitations of the study}

This study had two important limitations. First, it might be hard to get honest answers about patient dissatisfaction since their care-providers were behind the study. To minimize this, the questionnaires were administered in a conference room by a technician from another department not involved in the study and the questionnaires were free of any personal identification of the participants. The second limitation of this study was the response rate but, in this case, we may consider that technicians asked patients for their participation but clarified they felt free to say no and that decision could not affect their relationship with the study site and care-providers.

\section{CONCLUSION}

The decision-making process in the treatment of IPI is an important topic in clinical parasitology that has not been well studied in Cuba. More inclusion of patients in the process will increase their positive perceptions and satisfaction with health providers.

\section{Possible implications}

This study shows data on perception and satisfaction about the decision-making process related to clinical parasitology in a resource limited country, Cuba. Our results provide insights that may stimulate the implementation of strategies to strengthen the communication skills of clinicians and their full involvement with a shared treatment decision-making respecting beliefs and cultural tendencies.

Medical Sciences schools are responsible for producing graduates with competencies and attitudes to address health inequities and respond to priority health needs, society and policymakers should oversight the process.

\section{ACKNOWLEDGMENTS}

The authors thank the Scientific Council on the Centre of Hygiene, Epidemiology and Microbiology, Matanzas City, Cuba for their accompanying with this study since the very beginning. We also thank Zaida Fernandez Hernandez and Dr Fernando Acebo Figueroa for their technical support. The authors thank Seema Shah (NIH, USA) for her comments on an earlier version of this report. Special thanks to all patients who kindly accept to participate on the study.

\section{AUTHORS' NOTE}

R Canete, K Brito, D Guilhem, and KW Goodman conceived and designed the study; K Brito and R Cañete performed the study, coordinated and supervised data collection; all authors analysed and interpreted the data; R Cañete and KW Goodman drafted the paper; D Guilhem and K Brito critically revised the paper. All authors read and approved the final paper.

This study was supported by a grant from the Centre of Hygiene, Epidemiology and Microbiology, Matanzas City, Cuba. The funders had no role in study design, data collection and analysis, decision to publish, or preparation of the manuscript.

The authors have declared that no competing interests exist.

\section{REFERENCES}

1. Daryani A, Sharif M, Nasrolahei M, Khalilian A, Mohammadi A, Barzegar G. Epidemiological survey of the prevalence of intestinal parasites among schoolchildren in Sari, northern Iran. Trans R Soc Trop Med Hyg 2012; 106: 455-9.

2. Chacín-Bonilla L. Intestinal parasitic diseases as a global health problem. Invest Clin 2013; 54: 1-4.

3. Manderson L, Aagaard-Hansen J, Allotey P, Gyapong M, Sommerfeld J. Social Research on Neglected Diseases of Poverty: Continuing and Emerging Themes. PLoS Negl Trop Dis 2009; 3(2): e332. doi:10. 1371/journal. pntd.0000332.

4. White DB, Jonsen A, Lo B. Ethical challenge: when clinicians act as surrogates for unrepresented patients. Am J Crit Care 2012; 21: 202-7.

5. Campion EW, Morrissey S. A different model-medical care in Cuba. N Engl J Med 2013; 368: 297-9.

6. Domínguez-Alonso E, Zacca E. Sistema de salud de Cuba. Salud Publica Mex 2011; 53 (Suppl 2): S168-76.

7. Cañete Villafranca R, Guilhem D, Brito Pérez K. Paternalismo médico. Rev Méd Electrón 2013 Mar-Abr [cited: April 19, 2014]; 35. Available at: http://www.revmatanzas.sld.cu/revista\%20medica/ano\%202013/vol2\%20 2013/tema06.htm

8. Keck CW, Reed GA. The curious case of Cuba. Am J Public Health 2012; 102:e13-22.

9. Campion EW, Morrissey S. A Different Model - Medical Care in Cuba. N Engl J Med 2013; 368: 4.

10. Doria MF, Abubakar I, Syed Q, Hughes S, Hunter PR. Perceived causes of sporadic cryptosporidiosis and their relation to sources of information. J Epidemiol Community Health 2006; 60: 745-50.

11. World Health Organization: "Equity Team" definition. Health and Human Rights and Equity Working Group Draft Glossary Unpublished 2005. 2005 cited by Solar O, Irwin A: A conceptual framework for action on the social determinants of health. Geneva: World Health Organization; 2010.

12. Pons-Vigués M, Diez E, Morrison J, Salas-Nicás S, Hoffmann R, Burstrom B et al. Social and health policies or interventions to tackle health inequalities in European cities: a scoping review. BMC Public Health 2014; 14: 198. 
13. Marmot M, Bell R. Fair society, healthy lives. Public Health 2012; 126 (Suppl 1): S4-10

14. Cañete R, Díaz MM, Avalos García R, Laúd Martinez PM, Manuel Ponce F. Intestinal parasites in children from a day care centre in matanzas city, cuba. PLoS One 2012; 7: e51394.

15. Escalona CR, Alfonso de León JA, Álvarez MC, Cañete R. Fasciolosis aguda: presentación de un caso de Cuba. Rev Chilena Infectol 2012; 29: 543-6.

16. Parmelli E, Amato L, Saitto C, Davoli M; Gruppo di Lavoro DECIDE Italia. DECIDE: developing and evaluating communication strategies to support informed decisions and practice based on evidence. Recenti Prog Med 2013; 104: 522-31.

17. Iñiguez L. Aproximación a la evolución de los cambios en los servicios de salud en Cuba. Rev Cub de Salud Pública. 2012 Ene-Mar; 38.

18. Cañete R, Prior A, Brito K, Guilhem D, Novaes MR, Goodman KW. Development of an institutional curriculum in ethics and public health. Acta Bioeth 2013; 19: 251-7.

\section{Appendix 1. Open Questionnaire}

1. What do you know about intestinal parasitic infection?

2. Are intestinal parasites a public health problem worldwide?

3. Are intestinal parasites frequent in Cuba?

4. In your opinion, who is the main specialist to visit in case of intestinal parasitic infection?

5. Do you consider important to discuss with your doctor the different alternatives or therapies to treat parasites when you are infected?

6. The specialists respect your decision when evaluate the treatment options?

7. You fill comfortable receiving information about intestinal parasites?

8. In your opinion, which is the best scenario to receive information about intestinal parasites or others health problems?

9. Are you satisfied with the attention received in this center?

10. In your opinion, is this center accessible for all population?

11. Are you able to return to this center in case of need? 